\title{
The Influence of Warm Rolling on Microstructure and Deformation Behavior of High Manganese Steels
}

\author{
Marco Haupt ${ }^{1, *}$, Max Müller ${ }^{1}$, Christian Haase ${ }^{2}{ }^{(0)}$, Simon Sevsek ${ }^{2}{ }^{(0}$, Frederike Brasche ${ }^{3}$, \\ Alexander Schwedt ${ }^{4}$ and Gerhard Hirt ${ }^{1}$ \\ 1 Institute of Metal Forming, RWTH Aachen University, 52072 Aachen, Germany \\ 2 Steel Institute, RWTH Aachen University, 52072 Aachen, Germany \\ 3 Institute of Physical Metallurgy and Metal Physics, RWTH Aachen University, 52074 Aachen, Germany \\ 4 Central Facility for Electron Microscopy, RWTH Aachen University, 52074 Aachen, Germany \\ * Correspondence: marco.haupt@ibf.rwth-aachen.de; Tel.: +49-241-80-93527
}

Received: 17 June 2019; Accepted: 17 July 2019; Published: 18 July 2019

\begin{abstract}
In this work, a Fe-23Mn-0.3C-1Al high manganese twinning-induced plasticity (TWIP) steel is subjected to varying warm rolling procedures in order to increase the yield strength and maintain a notable ductility. A comprehensive material characterization allows for the understanding of the activated deformation mechanisms and their impact on the resulting microstructure, texture, and mechanical properties. The results show a significant enhancement of the yield strength compared to a fully recrystallized Fe-23Mn-0.3C-1Al steel. This behavior is mainly dominated by the change of the active deformation mechanisms during rolling. Deformation twinning is very pronounced at lower temperatures, whereas this mechanism is suppressed at $500{ }^{\circ} \mathrm{C}$ and a thickness reduction of up to $50 \%$. The mechanical properties can be tailored by adjusting rolling temperature and thickness reduction to desired applications.
\end{abstract}

Keywords: high manganese steel; warm rolling; processing; microstructure; texture; mechanical properties; deformation behavior

\section{Introduction}

High manganese twinning-induced plasticity (TWIP) steels are well known for their excellent mechanical properties in terms of exceptional ductility and high tensile strength, which is of high relevance for crash relevant automotive applications. Compared to industrially applied advanced high strength steels, e.g., dual phase steels, fully recrystallized high manganese steels exhibit a comparatively low yield strength, which represents a decisive disadvantage of this class of steel. In order to substantially increase the yield strength of high manganese TWIP steels, numerous approaches have been discussed in the literature such as prestraining [1], grain refinement [2], micro alloying [3], partial recrystallization [4], severe plastic deformation [5], reversion annealing [6] and recovery annealing [7]. Present limitations of these approaches, such as precise temperature control, pronounced anisotropy, or extraordinary degrees of deformation, prevent the use for industrial production routes.

Warm rolling represents a promising alternative processing method to substantially increase the yield strength of high manganese steels [8]. Hence, the impact of warm rolling parameters on microstructure, texture and mechanical properties of a high manganese TWIP steel is investigated in the present study. 
The concept of warm rolling takes advantage of the temperature dependence of the stacking fault energy (SFE), which determines the activated deformation mechanisms in high manganese steels. In addition to temperature, the SFE is mainly dependent on chemical composition and grain size. Deformation twinning is the predominant deformation mechanism in the SFE range of 20 to $60 \mathrm{~mJ} / \mathrm{m}^{2}$, in addition to dislocation glide. Above $60 \mathrm{~mJ} / \mathrm{m}^{2}$ the deformation mechanism changes mainly to slip [9]. This dependency in behavior on temperature and therefore the SFE of the deformation mechanisms in high manganese TWIP steels was also reported by [10-12]. The presented results indicate a change of the predominant deformation mechanism from mechanical twinning to dislocation glide with increasing temperature. By rolling at elevated temperatures (higher SFE) and applying the warm-rolled material at room temperature (lower SFE), the contribution of mechanical twinning and dislocation slip can be tailored in both temperature-deformation regimes in order to achieve superior mechanical properties. In order to accomplish this, it is necessary to prevent dynamic recrystallization during rolling, which is typically observed during hot deformation of austenitic TWIP steels at temperatures above $\sim 750{ }^{\circ} \mathrm{C}[8,13]$.

Texture evolution in austenitic steels such as TWIP steels strongly depends on the SFE. Alloys with low SFE values, e.g., $\alpha$-brass, develop a so-called brass-type rolling texture, which is characterized by a strong $\{110\}<112>$ brass and weak $\{552\}<115>$ copper twin (CuT), $\{110\}<100>$ goss, and $\{123\}<634>$ $\mathrm{S}$ texture components, as well as a weak $\gamma$-fiber $(<111>/ / \mathrm{ND})[14,15]$. A brass-type texture is caused by latent hardening due to planar dislocation glide and the activation of mechanical twinning [16]. In contrast, medium to high SFE materials like copper tend to form a texture consisting of pronounced $\{112\}<111>$ copper $(\mathrm{Cu})$, brass and $\mathrm{S}$ texture components. Therefore, such type of texture is called copper-type texture [17-19]. In previous works the texture evolution during cold rolling of different TWIP steels was investigated. In general, TWIP steels have the tendency to develop a brass-type rolling texture [18-22].

In order to investigate the impact of warm rolling parameters, such as temperature and thickness reduction on microstructure, texture and deformation behavior, a Fe-23Mn-0.3C-1Al TWIP steel was chosen for this study. The steel was processed at warm rolling temperatures ranging from $200{ }^{\circ} \mathrm{C}$ to $500{ }^{\circ} \mathrm{C}$ with thickness reductions ranging from $50 \%$ to $80 \%$. Mechanical properties were analyzed by uniaxial tensile tests, whereas the resulting microstructure and texture evolution was characterized by electron backscatter diffraction (EBSD) and X-ray diffraction (XRD) measurements.

\section{Materials and Methods}

\subsection{Material Processing}

The chemical composition of the investigated Fe-23Mn-0.3C-1 Al high manganese steel is given in Table 1. The material was ingot-cast in a vacuum induction furnace. The $100 \mathrm{~kg}$ ingot was then forged at $1150{ }^{\circ} \mathrm{C}$ to reduce the thickness from $140 \mathrm{~mm}$ to $50 \mathrm{~mm}$. A subsequent homogenization annealing at $1150^{\circ} \mathrm{C}$ for $5 \mathrm{~h}$ in an argon atmosphere was applied in order to reduce micro-segregations. The homogenized ingot was subsequently hot-rolled at $1150{ }^{\circ} \mathrm{C}$ to further reduce the sheet thickness to $4.0 \mathrm{~mm}$, followed by air cooling.

Table 1. Chemical composition of the investigated Fe-23Mn-0.3C-1Al high manganese steel.

\begin{tabular}{ccccccccccc}
\hline Element & Fe & C & Si & Mn & P & S & Al & Ni & Mo & Cr \\
\hline wt. $\%$ & Bal. & 0.322 & 0.053 & 22.45 & 0.008 & 0.008 & 0.995 & 0.027 & 0.008 & 0.020 \\
\hline
\end{tabular}


Afterwards, the hot strips were warm-rolled in 7-10 passes in the temperature range between $200{ }^{\circ} \mathrm{C}$ and $500{ }^{\circ} \mathrm{C}$ on a four-high rolling mill. The rolling degree was varied from $50 \%$ to $80 \%$. In addition, a cold rolled strip with $2.0 \mathrm{~mm}$ thickness and 50\% rolling degree achieved in seven rolling passes was used for comparison of microstructure and mechanical properties. Table 2 gives an overview of the process parameter combinations and the process scheme of the warm rolling process. In order to compensate the temperature loss due to transport of the strip from furnace to rolling mill, the furnace temperature $\left(\mathrm{T}_{\mathrm{F}}\right)$ was set $20-70{ }^{\circ} \mathrm{C}$ higher than the designated rolling temperature $\left(T_{R}\right)$. Consistent rolling temperatures were achieved by reheating of the strips for $5 \mathrm{~min}$ in between consecutive rolling passes.

Table 2. Process parameter combinations (marked with an $\mathrm{x}$ ) and process scheme of warm rolling.

\begin{tabular}{|c|c|c|c|c|c|c|}
\hline \multicolumn{2}{|c|}{ Temperature $\left({ }^{\circ} \mathrm{C}\right)$} & \multicolumn{4}{|c|}{ Thickness Reduction (\%) } & Process Scheme \\
\hline $\mathrm{T}_{\mathrm{R}}$ & $\mathrm{T}_{\mathrm{F}}$ & 50 & 60 & 70 & 80 & \multirow{7}{*}{$\underset{0}{\substack{\mathrm{T}_{\mathrm{F}} \\
\mathrm{T}_{\mathrm{R}}}}$} \\
\hline 25 & - & $x$ & & & & \\
\hline 200 & 220 & $\mathrm{x}$ & & & & \\
\hline 300 & 340 & $x$ & & & & \\
\hline 400 & 460 & $x$ & & & & \\
\hline 450 & 510 & $x$ & & & & \\
\hline 500 & 570 & $x$ & $x$ & $\mathrm{x}$ & $\mathrm{x}$ & \\
\hline
\end{tabular}

\subsection{Sample Preparation and Characterization}

EBSD and XRD specimens with the dimensions $10 \times 12 \mathrm{~mm}^{2}$ (transverse direction (TD) and rolling direction (RD)) were waterjet cut from the cold-rolled and warm-rolled sheets. Both EBSD and XRD specimens were ground utilizing SiC-paper up to 4000 grit followed by mechanical polishing using diamond suspension up to $1 \mu \mathrm{m}$. Finally, the XRD samples were electropolished at room temperature. EBSD samples were mechanically polished to $0.25 \mu \mathrm{m}$ and subsequently electropolished.

The resulting microstructure in the RD-TD section of the cold-rolled and warm-rolled strips was examined by EBSD using a JEOL JSM 7000F scanning electron microscope (JEOL Ltd., Tokyo, Japan) equipped with an EDAX Hikari EBSD detector (EDAX Inc., Mahwah, NJ, USA). The measurements were performed with an acceleration voltage of $20 \mathrm{kV}$ and a step size of $200 \mathrm{~nm}$. EBSD data was analyzed using the EDAX OIM Analysis 8 software (EDAX Inc., Mahwah, NJ, USA).

Macro-texture measurements were conducted in a Bruker D8 Advance diffractometer (Bruker Corporation, Billerica, MA, USA), which was equipped with a HI-STAR area detector and operated with iron-radiation at $30 \mathrm{kV}$ and $25 \mathrm{~mA}$. Three incomplete $\left(0-85^{\circ}\right)\{111\}-,\{200\}-$, and $\{220\}$-pole figures were measured and the corresponding orientation distribution functions (ODF) were calculated using the MATLAB ${ }^{\circledR}$-based MTEX toolbox $[23,24]$. Besides, volume fractions of selected texture components were computed applying a spread of $15^{\circ}$ around the ideal orientation. XRD analysis was performed on the mid-layer of the sheets in the RD-TD section.

For characterization of mechanical properties flat tensile specimens with a gauge length of $30 \mathrm{~mm}$, a gauge width of $6 \mathrm{~mm}$ and a fillet radius of $20 \mathrm{~mm}$ were waterjet cut from the rolled sheets with tensile direction parallel to RD. After polishing of the edges, quasi-static tensile tests at room temperature were performed utilizing a Zwick Z250 universal testing machine (ZwickRoell, Ulm, Germany) at a constant strain rate of $0.001 \mathrm{~s}^{-1}$. 


\section{Results}

\subsection{Microstructure}

An EBSD inverse pole figure (IPF) map of the initial hot-rolled Fe-23Mn-0.3C-1Al steel is displayed in Figure 1. Prior to cold or warm rolling the material exhibits an equiaxial grain structure with a relatively high mean grain size of $\sim 30 \mu \mathrm{m}$. Twin boundaries are not present in the hot-rolled samples.
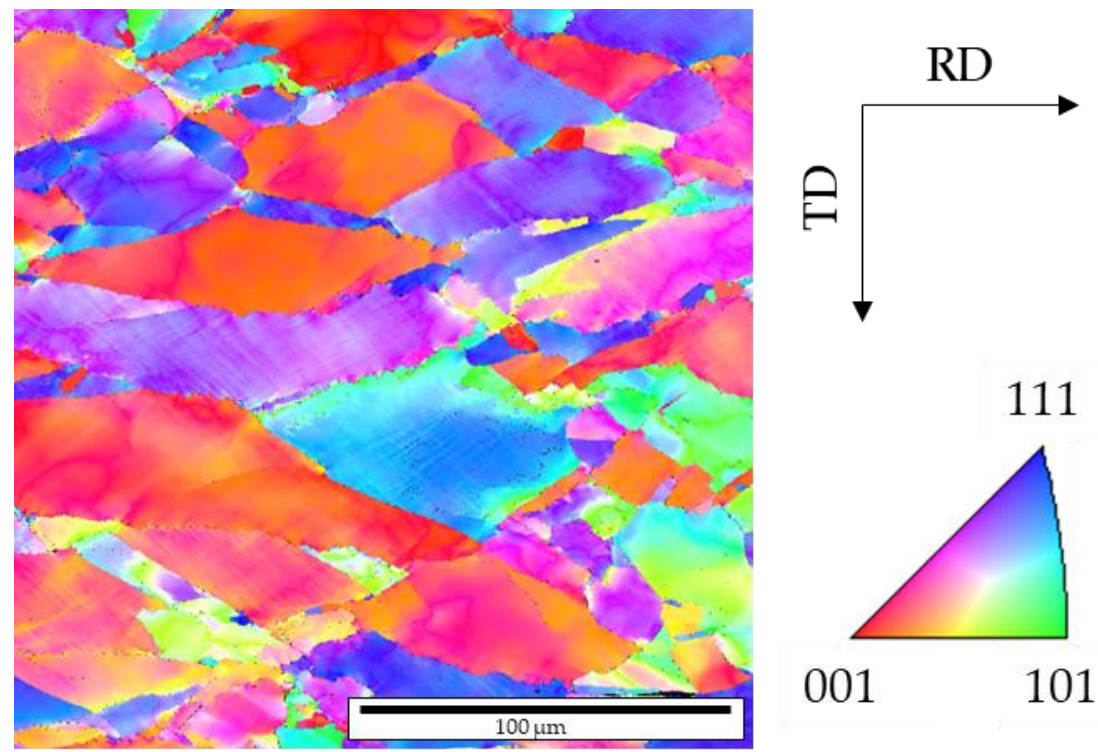

Figure 1. Electron backscatter diffraction inverse pole figure (EBSD-IPF) map of hot-rolled Fe-23Mn-0.3C-1Al steel. The IPF takes the rolling direction (RD) as reference axis.

Figure 2 shows EBSD image quality (IQ) maps of the resulting microstructure of the Fe-23Mn-0.3C-1Al high manganese steel after cold rolling and warm rolling at temperatures ranging from $200^{\circ} \mathrm{C}$ to $500{ }^{\circ} \mathrm{C}$, respectively. Detected deformation twin boundaries $\left(60^{\circ}<111>\right)$ are indicated with the color blue. For all samples, a severely deformed austenitic grain structure can be observed. However, the fraction of detected deformation twin boundaries decreases significantly at higher warm rolling temperatures. The material that was warm-rolled at $200{ }^{\circ} \mathrm{C}$ and $300^{\circ} \mathrm{C}$ shows a high fraction of deformation twin boundaries and is therefore comparable to the cold-rolled sample. In the material that was warm-rolled at $400{ }^{\circ} \mathrm{C}$ the deformation twin boundaries decrease drastically compared to the material rolled at lower temperatures. Despite the drastic decrease, the material still shows a significant fraction of twin boundaries. The material which was warm-rolled at $450{ }^{\circ} \mathrm{C}$ exhibits an even lower amount of deformation twin boundaries while practically no twin boundaries are present in the material that was warm-rolled at $500{ }^{\circ} \mathrm{C}$. This correlation between warm rolling temperature and detected deformation twin boundaries indicates a change of the predominant deformation mechanism during warm rolling from twinning to slip in the temperature range of 400 to $500{ }^{\circ} \mathrm{C}$. By warm rolling the Fe-23Mn-0.3C-1Al high manganese steel at $500{ }^{\circ} \mathrm{C}$ it is possible to achieve a thickness reduction of $50 \%$ primarily based on the slip mechanism.

At even higher thickness reductions at a comparably high warm rolling temperature of $500{ }^{\circ} \mathrm{C}$ deformation twin boundaries can still be observed, as shown in Figure 3. The material with a thickness reduction of $60 \%$ exhibits an amount of deformation twin boundaries comparable to the material that was warm-rolled at $450{ }^{\circ} \mathrm{C}$ and $50 \%$ thickness reduction. At a higher deformation degree of $70 \%$, the amount of deformation twin boundaries only increases slightly. The overall observed grain structure is strongly elongated parallel to RD due to the high plastic deformation applied during rolling. 

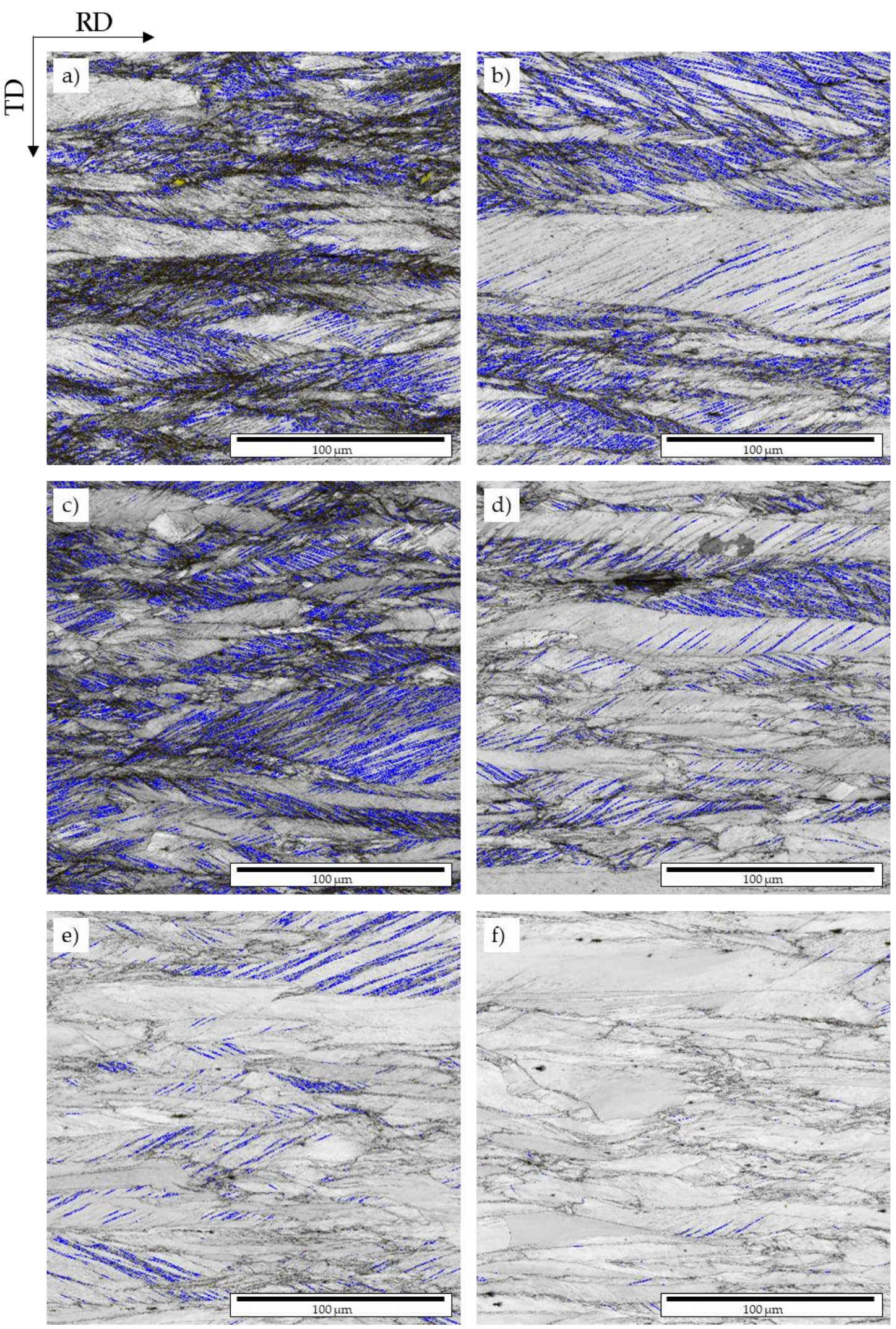

Figure 2. EBSD-IQ maps of the investigated steel deformed to $50 \%$ thickness reduction by (a) cold rolling and warm rolling at (b) $200{ }^{\circ} \mathrm{C},(\mathbf{c}) 300{ }^{\circ} \mathrm{C}$, (d) $400{ }^{\circ} \mathrm{C}$, (e) $450{ }^{\circ} \mathrm{C}$ and (f) $500{ }^{\circ} \mathrm{C}$. Blue lines indicate deformation twin boundaries $\left(60^{\circ}<111>\right)$. 

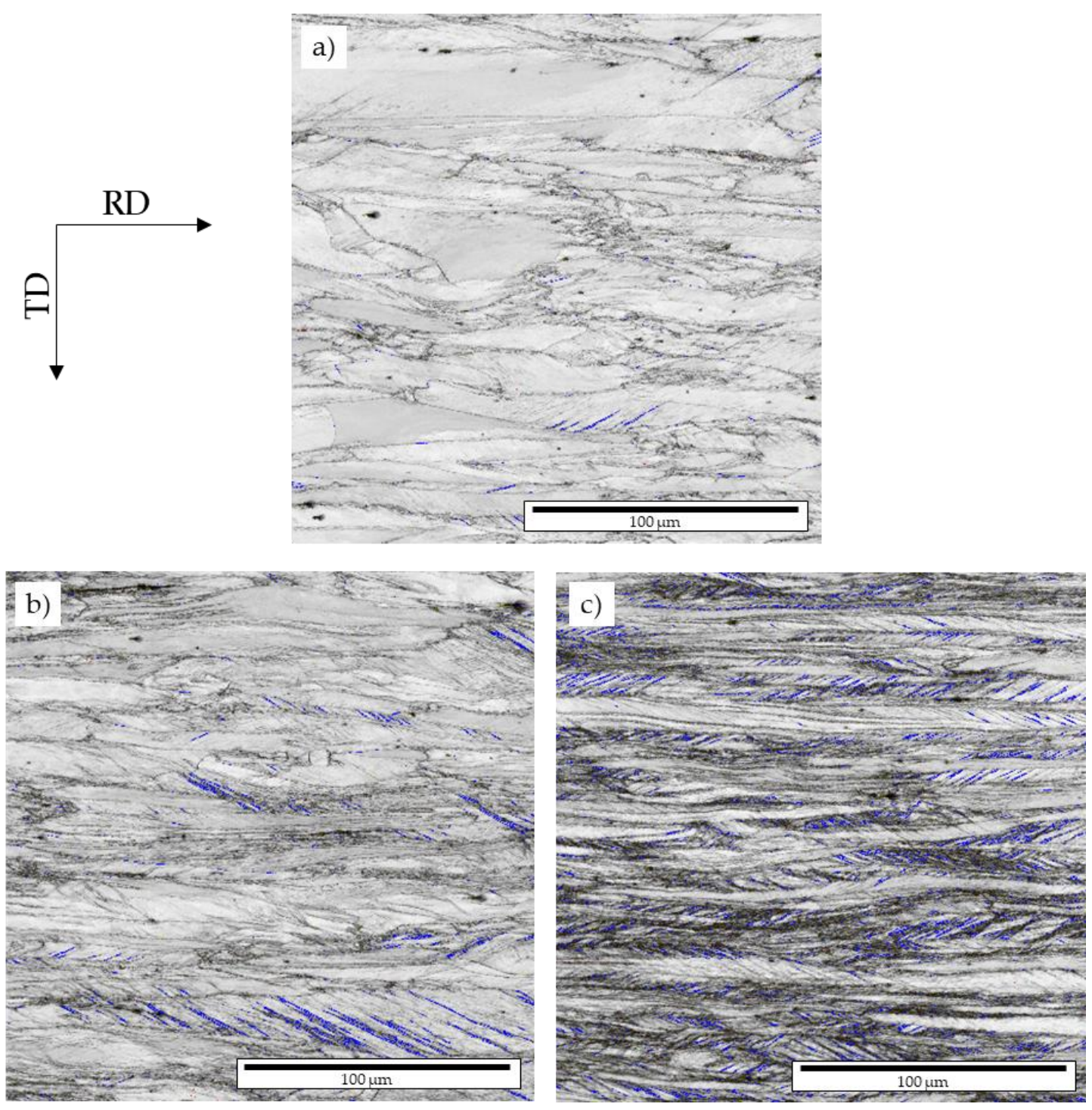

Figure 3. EBSD-IQ maps of the investigated steel warm-rolled at $500{ }^{\circ} \mathrm{C}$ to thickness reductions of (a) $50 \%$, (b) $60 \%$, and (c) $70 \%$. Blue lines indicate deformation twin boundaries $\left(60^{\circ}<111>\right.$ ).

\subsection{Influence of Rolling Temperature on Texture Evolution During Warm Rolling}

The texture formation of the investigated material after rolling in the temperature range between $25^{\circ} \mathrm{C}$ and $500{ }^{\circ} \mathrm{C}$ to a rolling reduction of $50 \%$ is illustrated in Figure 4 by means of $\varphi_{2}=45^{\circ}$ sections of the ODF. The ideal location of the relevant texture components is schematically depicted (Figure 4, top left corner) and the corresponding definition of the texture components can be found in Table 3 . In addition to the ODF sections, Figure $4 \mathrm{~h}$ displays the calculated volume fractions of selected texture components. The temperature dependent texture formation in the present investigation can be divided into three stages: $25-300{ }^{\circ} \mathrm{C}$ (Stage I), $400{ }^{\circ} \mathrm{C}$ (stage II), and $450-500{ }^{\circ} \mathrm{C}$ (stage III). Rolling at $25^{\circ} \mathrm{C}$ to a deformation degree of $50 \%$ results in the development of a relatively strong brass texture component along with weaker goss, $\mathrm{CuT}, \mathrm{E}+\mathrm{F}$, and $\mathrm{Cu}$ texture components. With increasing rolling temperature, the intensity of the brass texture component slightly decreases. This decrease is accompanied by a stagnation in volume fractions of the $\mathrm{Cu}$ and $\mathrm{CuT}$ texture component and a steady decrease in $\mathrm{E}+\mathrm{F}$ texture components. Stage II $\left(400^{\circ} \mathrm{C}\right)$ represents an intermediate state. The brass texture component reaches a minimum and a remarkable drop in volume fraction of the CuT texture component is detected. Nevertheless, the volume fraction of the $\mathrm{Cu}$ texture component remains at a similar level. Additionally, a small volume fraction of the cube texture component is observed. The third stage comprises the 
material states at $450{ }^{\circ} \mathrm{C}$ and $500{ }^{\circ} \mathrm{C}$. A high intensity of Cu-oriented grains is present and the $\alpha$-fiber components (brass and goss) intensify, albeit to a smaller extent. In addition, the $\mathrm{CuT}$ and $\gamma$-fiber components $(\mathrm{E}+\mathrm{F})$ weaken strongly.

Figure 5 shows the texture evolution during rolling at $500{ }^{\circ} \mathrm{C}$ with a thickness reduction ranging from $50 \%$ to $80 \%$ as $\varphi_{2}=45^{\circ}$ ODF sections and the evolution of the volume fraction of the main texture components. With an increasing rolling degree, the volume fractions of the $\mathrm{CuT}$ and $\mathrm{E}+\mathrm{F}$ texture components increase, whereas the amount of $\mathrm{Cu}$-oriented grains decreases. The texture evolution of the present material during cold rolling in the deformation range between $50 \%$ and $80 \%$ has already been investigated in $[19,25,26]$. Haase et al. reported about the formation of a $\gamma$-fiber accompanied by a strengthening of the $\alpha$-fiber and a constant low level of Cu-texture component [19]. In the present work, the $\alpha$-fiber intensifies with increasing rolling degree as well. However, both a stronger $\mathrm{Cu}$-texture component and an absence of the $\gamma$-fiber is observed. Therefore, it can be concluded that a temperature increase from $25^{\circ} \mathrm{C}$ to $500{ }^{\circ} \mathrm{C}$ also effects texture evolution.

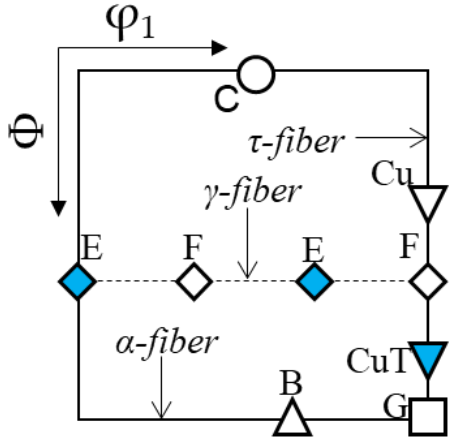

a)

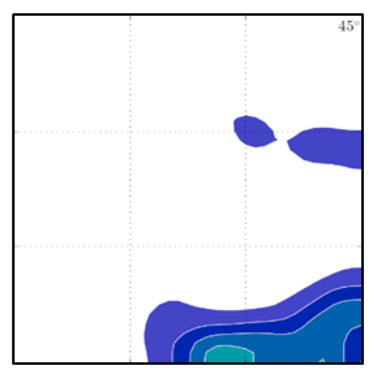

d)

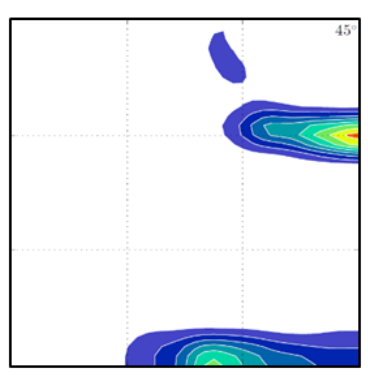

g)

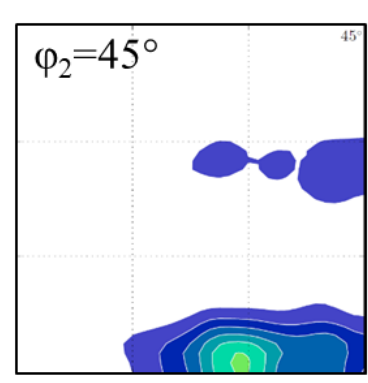

b)

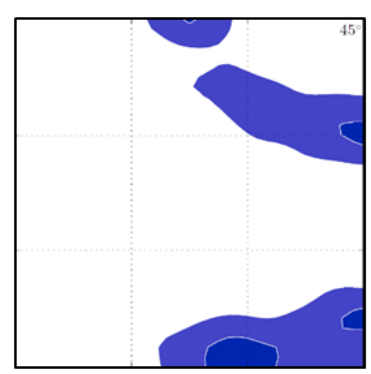

e)

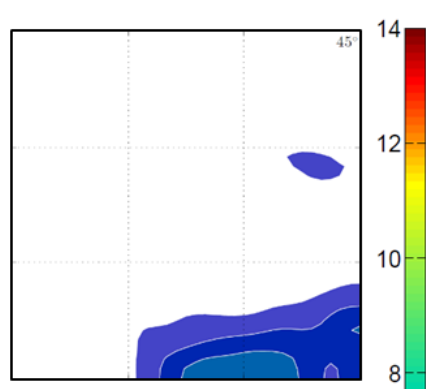

c)

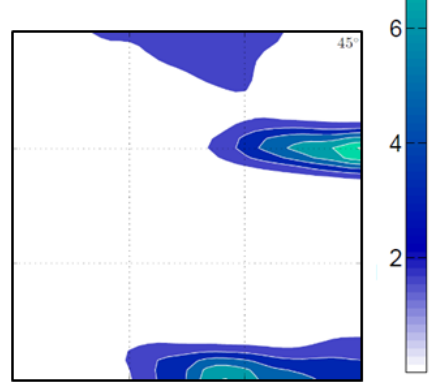

f)

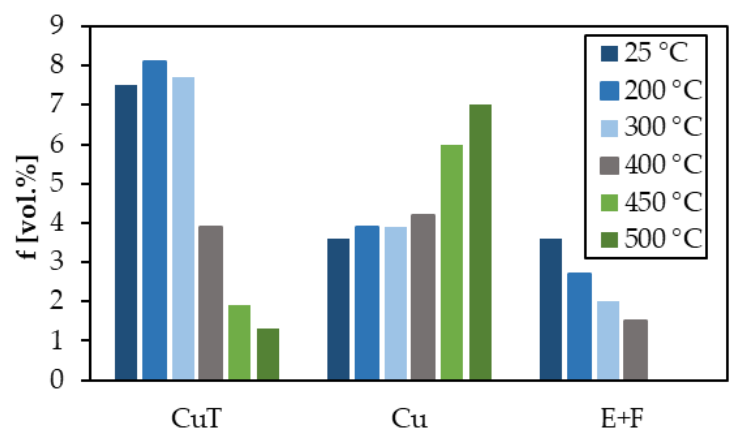

h)

Figure 4. Texture formation of the material rolled to $50 \%$ thickness reduction at different temperatures. (a) Schematic presentation of the ideal texture component in the orientation distribution functions (ODF) section at $\varphi_{2}=45^{\circ}$. ODF sections at $\varphi_{2}=45^{\circ}$ for (b) $25^{\circ} \mathrm{C}$, (c) $200{ }^{\circ} \mathrm{C}$, (d) $300{ }^{\circ} \mathrm{C},(\mathbf{e}) 400{ }^{\circ} \mathrm{C}$, (f) $450{ }^{\circ} \mathrm{C}$, (g) $500^{\circ} \mathrm{C}$, and (h) presentation of the volume fractions of selected texture components. 
Table 3. Definition of texture components illustrated in Figures 4 and 5.

\begin{tabular}{|c|c|c|c|c|}
\hline Component & Symbol & Miller Indices & $\begin{array}{l}\text { Euler Angles } \\
\left(\varphi_{1}, \Phi, \varphi_{2}\right)\end{array}$ & Fiber \\
\hline Brass (B) & $\triangle$ & $\{110\}<112>$ & $(55,90,45)$ & $\alpha, \beta$ \\
\hline Goss (G) & $\square$ & $\{110\}<100>$ & $(90,90,45)$ & $\alpha, \tau$ \\
\hline Cube (C) & & $\{001\}<100>$ & $(45,0,45)$ & - \\
\hline E & & $\{111\}<110>$ & $(0 / 60,55,45)$ & $\gamma$ \\
\hline $\mathrm{F}$ & $>$ & $\{111\}<112>$ & $(30 / 90,55,45)$ & $\gamma$ \\
\hline Copper $(\mathrm{Cu})$ & $\nabla$ & $\{112\}<111>$ & $(90,35,45)$ & $\beta, \tau$ \\
\hline Copper Twin (CuT) & V & $\{552\}<115>$ & $(90,74,45)$ & $\tau$ \\
\hline $\begin{array}{l}\alpha \text {-fiber } \\
\beta \text {-fiber } \\
\tau \text {-fiber } \\
\gamma \text {-fiber }\end{array}$ & \multicolumn{4}{|c|}{$\begin{array}{c}<110>\text { parallel to ND } \\
<110>\text { tilted } 60^{\circ} \text { from ND towards RD } \\
<110>\text { parallel TD } \\
<111>\text { parallel ND }\end{array}$} \\
\hline
\end{tabular}

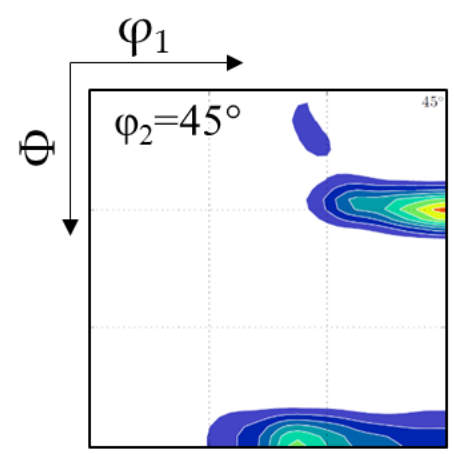

a)

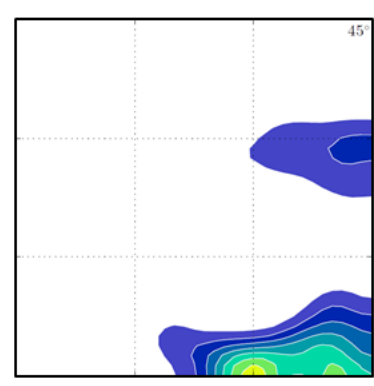

d)

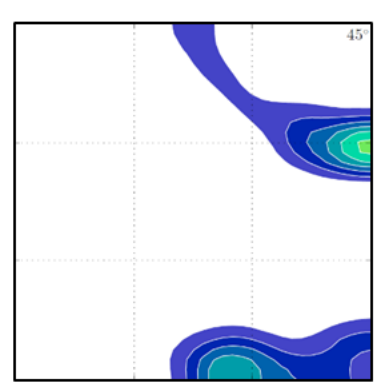

b)

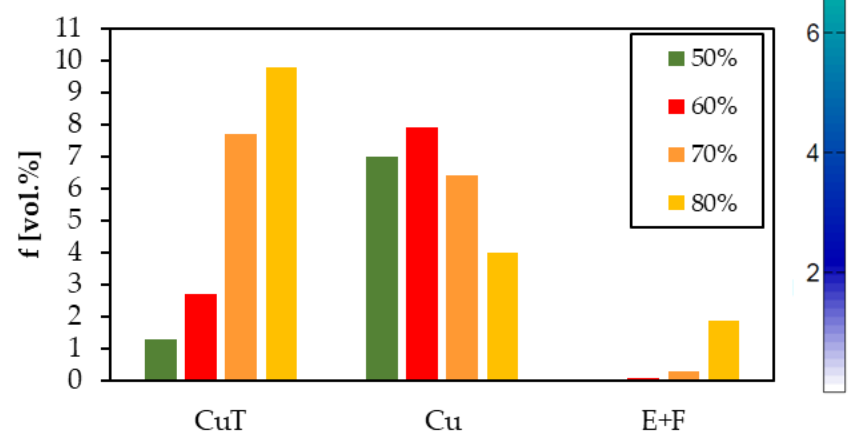

e)

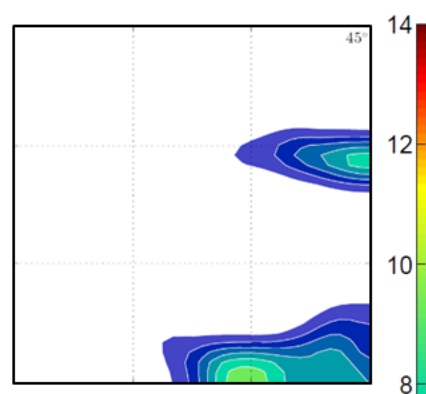

c)

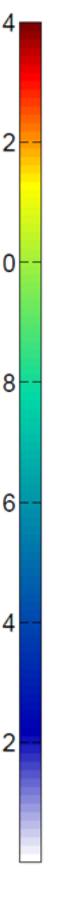

Figure 5. Texture evolution of the material rolled at $500{ }^{\circ} \mathrm{C}$ to different rolling reductions. ODF sections at $\varphi_{2}=45^{\circ}$ of (a) $50 \%$, (b) $60 \%$, (c) $70 \%$, and (d) $80 \%$ and (e) presentation of the volume fractions of selected texture components.

\subsection{Mechanical Properties}

Figure 6 shows the engineering stress-strain curves derived from uniaxial tensile tests at room temperature of the cold-rolled and warm-rolled material. The corresponding mechanical parameters are summarized in Table 4. The cold-rolled high manganese steel possesses the highest strength but has limited ductility. At a constant thickness reduction of $50 \%$ the strength level decreases with increasing rolling temperature. A warm-rolling temperature of $200^{\circ} \mathrm{C}$ results in a yield strength (YS) of $1092 \mathrm{MPa}$, 
whereas a warm rolling temperature of $500{ }^{\circ} \mathrm{C}$ leads to a significantly lower yield strength of $788 \mathrm{MPa}$. The loss of strength is accompanied by a noticeable increase of uniform elongation (UE) and total elongation (TE). Compared to the material warm-rolled at $200{ }^{\circ} \mathrm{C}$ the material warm-rolled at $500{ }^{\circ} \mathrm{C}$ exhibits an almost four times higher total elongation of $38.5 \%$.

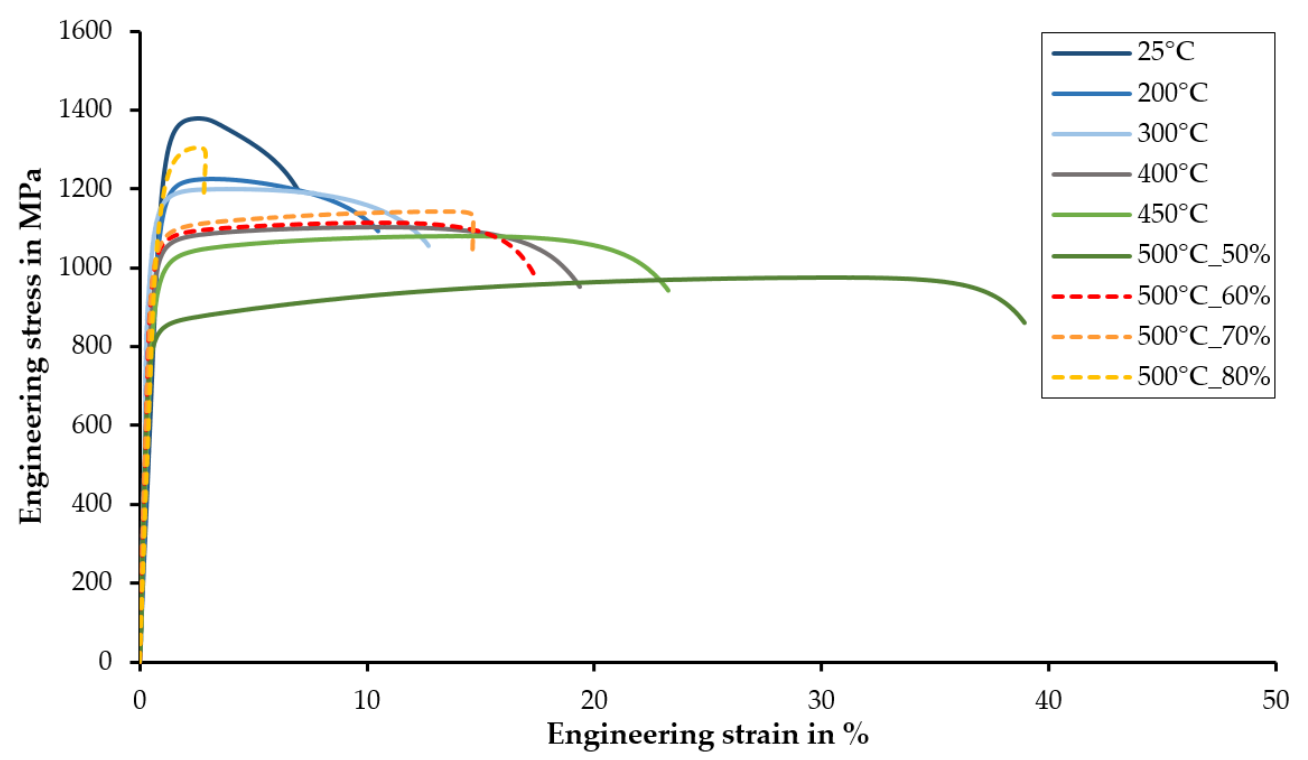

Figure 6. Engineering stress-strain curves of the investigated Fe-23Mn-0.3C-1Al steel subjected to varying rolling procedures.

Table 4. Mechanical properties of the investigated Fe-23Mn-0.3C-1Al steel depending on rolling temperature and thickness reduction.

\begin{tabular}{cccccc}
\hline $\begin{array}{c}\text { Rolling } \\
\text { Temperature } \\
\left({ }^{\circ} \mathbf{C}\right)\end{array}$ & $\begin{array}{c}\text { Thickness } \\
\text { Reduction } \\
(\mathbf{\%})\end{array}$ & $\begin{array}{c}\text { Yield Strength } \\
\mathbf{( M P a )}\end{array}$ & $\begin{array}{c}\text { Tensile } \\
\text { Strength } \\
\mathbf{( M P a )}\end{array}$ & $\begin{array}{c}\text { Uniform } \\
\text { Elongation } \\
\mathbf{( \% )}\end{array}$ & $\begin{array}{c}\text { Total } \\
\text { Elongation } \\
\mathbf{( \% )}\end{array}$ \\
\hline 25 & 50 & 1274 & 1379 & 1.6 & 6.1 \\
200 & 50 & 1081 & 1227 & 2.8 & 9.8 \\
300 & 50 & 1054 & 1200 & 3.3 & 12.3 \\
400 & 50 & 959 & 1103 & 10.2 & 18.9 \\
450 & 50 & 942 & 1082 & 13.6 & 22.6 \\
500 & 50 & 788 & 975 & 30.1 & 38.5 \\
500 & 60 & 999 & 1114 & 10.0 & 17.0 \\
500 & 70 & 1015 & 1144 & 12.7 & 14.1 \\
500 & 80 & 1133 & 1305 & 1.6 & 1.9 \\
\hline
\end{tabular}

By increasing the thickness reduction at a constant warm rolling temperature of $500^{\circ} \mathrm{C}$, the yield and ultimate tensile strength (UTS) also increase. A thickness reduction of $80 \%$ results in an ultimate tensile strength of $1305 \mathrm{MPa}$ but poor ductility. By increasing the thickness reduction to $60 \%$, the ultimate tensile strength can be increased to $1114 \mathrm{MPa}$ at a reasonable uniform elongation of $10.0 \%$. The comparison of a thickness reduction of $60 \%$ and $70 \%$ therefore shows only a slight difference regarding strength and ductility.

In comparison to a fully recrystallized Fe-23Mn-0.3C-1Al steel (YS $=356 \mathrm{MPa}$, UTS $=787 \mathrm{MPa}$, $\mathrm{UE}=56.8 \%, \mathrm{TE}=62.1 \%$, mean grain size $=3.1 \mu \mathrm{m}$ ), all warm-rolled materials investigated exhibit a significantly higher yield and ultimate tensile strength. 


\section{Discussion}

The EBSD-IQ maps (Figure 2) confirm the strong temperature dependence of the activated deformation mechanisms during rolling. Twinning is the predominant deformation mechanism in the range of $25^{\circ} \mathrm{C}$ to $300^{\circ} \mathrm{C}$, which is indicated by the high fraction of detected deformation twin boundaries. This can also be observed in the according evolution of the crystallographic texture (Figure 4). The CuT texture component is a texture component which is associated with planar dislocation glide and deformation-induced twinning [19,27]. Thus, the volume fractions of the CuT component can be correlated with the densities of deformation twins. The constant high level of CuT volume fraction in the range from $25^{\circ} \mathrm{C}$ to $300{ }^{\circ} \mathrm{C}$ indicates that twinning is the predominant deformation mechanism during rolling, which has also been reported by Grajcar et al. [10]. The influence of this characteristic microstructure after rolling on the mechanical properties is shown in Figure 6. Due to the strain hardening effect of the already high fraction of deformation twin boundaries, the material exhibits a comparably high yield, and ultimate tensile strength. Therefore, the remaining low work hardening capacity results in a poor ductility and early fracture of the material.

Around the temperature threshold of $400{ }^{\circ} \mathrm{C}$ the predominant deformation mechanism shifts from twinning to dislocation glide, which can be concluded by the small volume fractions of the CuT texture component, as shown in Figure 4e. This correlates with the significantly lower amount of deformation twin boundaries detected in the corresponding EBSD-IQ map in Figure 2d. This is in accordance with Barbieri et al. [12], who report a continuous transition of the deformation mechanism with increasing SFE. During subsequent tensile testing at room temperature of the warm-rolled material, the remaining work hardening capacity of the twinning mechanism leads to a significant increase of uniform and total elongation, whereas the overall strength level decreases (Figure 6).

EBSD and XRD measurements of the material 50\% warm-rolled at even higher temperatures, e.g., $500{ }^{\circ} \mathrm{C}$, show that the twinning mechanism can almost be suppressed completely. This is indicated by the negligible amount of detected deformation twin boundaries (Figure 2f) and the low fraction of the CuT texture component (Figure $4 \mathrm{~h}$ ). The combination of the slip mechanism, also including cross slip, activated during warm rolling and the twinning mechanism activated during room temperature tensile testing results in excellent mechanical properties (Figure 6). It is important to note that the dynamic recrystallization of the material during rolling, which typically occurs during hot rolling $[8,13]$, was successfully prevented despite the comparably high temperature.

As displayed in Figure 3b,c and Figure 5, a thickness reduction higher than $50 \%$ at $500{ }^{\circ} \mathrm{C}$ warm rolling temperature without the presence of deformation twinning could not be achieved. This behavior can be explained with the observed texture components present at higher thickness reductions. Deformation twinning proceeds in $\mathrm{Cu}$ oriented grains. Consequently, a rise of the CuT texture component effects the elimination of the $\mathrm{Cu}$ texture (Figure 5). At high deformation degrees twin-matrix lamellae are rotated into the rolling plane and shear bands occur. This phenomenon is related to the onset of the $\mathrm{E}+\mathrm{F}$ texture components. By forming the $\mathrm{E}+\mathrm{F}$ texture components, in turn, the CuT texture component is consumed [19]. Hence, it must be assumed that the formation of shear bands prohibited an even steeper rise of the CuT texture component. The presence of a significant amount of deformation twin boundaries at higher thickness reduction again results in an increased yield and ultimate tensile strength but a drastically decreased ductility.

Despite the high deformation applied during rolling and the different strength-ductility combinations observed, the materials warm-rolled at temperatures higher than $300^{\circ} \mathrm{C}$ show a significant work-hardening behavior at room temperature. This is achieved by the activation of the twinning mechanism during the tensile tests at room temperature, which causes the notable work-hardening.

\section{Conclusions}

In this work, a Fe-23Mn-0.3C-1Al high manganese TWIP steel was processed by warm rolling at various warm rolling temperatures and thickness reductions in order to increase the yield strength and maintain a reasonable ductility, as compared to recrystallized counterparts. The resulting 
microstructure, texture, and mechanical properties were analyzed, and their correlation was discussed. The following conclusions can be drawn:

- The temperature dependence of the stacking fault energy can be used to control the predominant deformation mechanism of high manganese steels during rolling. The performed EBSD measurements and XRD texture analysis show that the formation of deformation twins can be suppressed at $500{ }^{\circ} \mathrm{C}$ and thickness reduction of up to $50 \%$.

- The specimens warm-rolled at temperatures higher than $300^{\circ} \mathrm{C}$ exhibit exceptional mechanical properties due to the combination of slip and twinning. The adjustment of rolling temperature and rolling degree allows for tailoring the mechanical properties in a wide range. The resulting uniform and total elongation can be increased by increasing the rolling temperature, whereas yield and ultimate tensile strength decrease accordingly. The material benefits from strain hardening due to the slip effect at elevated temperatures. The twinning mechanism during deformation at room temperature, i.e., after prior warm rolling, accordingly enables a certain ductility and work hardening potential of the warm-rolled high manganese steel.

- The yield strength and overall strength level of a high manganese TWIP steel could be notably improved by warm rolling. A reasonable uniform and ultimate elongation could be maintained. Compared to a fully recrystallized Fe-23Mn-0.3C-1Al steel, the warm-rolled material states exhibit superior mechanical properties, especially in terms of strength.

Author Contributions: Conceptualization, M.H.; formal analysis, M.H.; investigation, M.H., M.M., S.S., F.B. and A.S.; supervision, C.H. and G.H.; visualization, M.H. and M.M.; project administration, G.H.; writing-original draft, M.H. and M.M.

Funding: This research was funded by the Deutsche Forschungsgemeinschaft (DFG) within the Collaborative Research Centre (SFB) 761 "Stahl - ab initio; Quantenmechanisch geführtes Design neuer Eisenbasiswerkstoffe", project number 29898171.

Conflicts of Interest: The authors declare no conflict of interest. The funders had no role in the design of the study; in the collection, analyses, or interpretation of data; in the writing of the manuscript, or in the decision to publish the results.

\section{References}

1. Kusakin, P.; Belyakov, A.; Haase, C.; Kaibyshev, R.; Molodov, D.A. Microstructure evolution and strengthening mechanisms of Fe-23Mn-0.3C-1.5Al TWIP steel during cold rolling. Mater. Sci. Eng. A 2014, 617, 52-60. [CrossRef]

2. Ueji, R.; Tsuchida, N.; Terada, D.; Tsuji, N.; Tanaka, Y.; Takemura, A.; Kunishige, K. Tensile properties and twinning behavior of high manganese austenitic steel with fine-grained structure. Scr. Mater. 2008, 59, 963-966. [CrossRef]

3. Scott, C.; Remy, B.; Collet, J.L.; Cael, A.; Bao, C.; Danoix, F.; Malard, B.; Curfs, C. Precipitation strengthening in high manganese austenitic TWIP steels. Int. J. Mater. Res. 2011, 102, 538-549. [CrossRef]

4. Bouaziz, O.; Barbier, D. Benefits of recovery and partial recrystallization of nano-twinned austenitic steels. Adv. Eng. Mater. 2013, 15, 976-9794. [CrossRef]

5. Haase, C.; Kremer, O.; Hu, W.; Ingendahl, T.; Lapovok, R.; Molodov, D.A. Equal-channel angular pressing and annealing of a twinning-induced plasticity steel: Microstructure, texture, and mechanical properties. Acta Mater. 2016, 107, 239-253. [CrossRef]

6. Berrenberg, F.; Haase, C.; Barrales-Mora, L.A.; Molodov, D.A. Enhancement of the strength-ductility combination of twinning-induced/transformation-induced plasticity steels by reversion annealing. Mater. Sci. Eng. A 2017, 681, 56-64. [CrossRef]

7. Haase, C.; Barrales-Mora, L.A.; Molodov, D.A.; Gottstein, G. Tailoring the Mechanical Properties of a Twinning-Induced Plasticity Steel by Retention of Deformation Twins During Heat Treatment. Metall. Mater. Trans. A 2013, 44, 4445-4449. [CrossRef]

8. Belyakov, A.; Kaibyshev, R.; Torganchuk, V. Microstructure and Mechanical Properties of 18\%Mn TWIP/TRIP Steels Processed by Warm or Hot Rolling. Steel Res. Int. 2017, 88, 1600123. [CrossRef] 
9. Saeed-Akbari, A.; Imlau, J.; Prahl, U.; Bleck, W. Derivation and variation in composition-dependent stacking fault energy maps based on subregular solution model in high-manganese steels. Metall. Mater. Trans. A 2009, 40, 3076-3090. [CrossRef]

10. Grajcar, A.; Kozłowska, A.; Topolska, S.; Morawiec, M. Effect of Deformation Temperature on Microstructure Evolution and Mechanical Properties of Low-Carbon High-Mn Steel. Adv. Mater. Sci. Eng. 2018, 2018, 1-7. [CrossRef]

11. Zhang, J.; Di, H.; Mao, K.; Wang, X.; Han, Z.; Ma, T. Processing maps for hot deformation of a high-Mn TWIP steel: A comparative study of various criteria based on dynamic materials model. Mater. Sci. Eng. A 2013, 587, 110-122. [CrossRef]

12. Barbieri, F.D.; Castro Cerda, F.; Pérez-Ipiña, J.; Artigas, A.; Monsalve, A. Temperature Dependence of the Microstructure and Mechanical Properties of a Twinning-Induced Plasticity Steel. Metals 2018, 8, 262. [CrossRef]

13. Dolzhenko, P.; Tikhonova, M.; Kaibyshev, R.; Belyakov, A. Dynamically Recrystallized Microstructures, Textures, and Tensile Properties of a Hot Worked High-Mn Steel. Metals 2019, 9, 30. [CrossRef]

14. Hirsch, J.; Lücke, K. Overview no. 76: Mechanism of deformation and development of rolling textures in polycrystalline f.c.c. metals-I. Description of rolling texture development in homogeneous CuZn alloys. Acta Metall. 1988, 36, 2863-2882. [CrossRef]

15. Haase, C.; Barrales-Mora, L.A. Influence of deformation and annealing twinning on the microstructure and texture evolution of face-centered cubic high-entropy alloys. Acta Mater. 2018, 150, 88-103. [CrossRef]

16. Saleh, A.A.; Haase, C.; Pereloma, E.V.; Molodov, D.A.; Gazder, A.A. On the evolution and modelling of brass-type texture in cold-rolled twinning-induced plasticity steel. Acta Mater. 2014, 70, 259-271. [CrossRef]

17. Humphreys, F.J.; Hatherly, M. Recrystallization and Related Annealing Phenomena, 2nd ed.; Elsevier: Amsterdam, The Netherlands, 2004.

18. Bracke, L.; Verbeken, K.; Kestens, L.; Penning, J. Microstructure and texture evolution during cold rolling and annealing of a high Mn TWIP steel. Acta Mater. 2009, 57, 1512-1524. [CrossRef]

19. Haase, C.; Barrales-Mora, L.A.; Roters, F.; Molodov, D.A.; Gottstein, G. Applying the texture analysis for optimizing thermomechanical treatment of high manganese twinning-induced plasticity steel. Acta Mater. 2014, 80, 327-340. [CrossRef]

20. Lü, Y.; Molodov, D.A.; Gottstein, G. Correlation Between Microstructure and Texture Development in a Cold-rolled TWIP Steel. ISIJ Int. 2011, 51, 812-817. [CrossRef]

21. Vercammen, S.; Blanpain, B.; Cooman, B.C.D.; Wollants, P. Cold rolling behaviour of an austenitic Fe-30Mn-3Al-3Si TWIP-steel: The importance of deformation twinning. Acta Mater. 2004, 52, 2005-2012. [CrossRef]

22. Haase, C.; Chowdhury, S.G.; Barrales-Mora, L.A.; Molodov, D.A.; Gottstein, G. On the Relation of Microstructure and Texture Evolution in an Austenitic Fe-28Mn-0.28C TWIP Steel During Cold Rolling. Metall. Mater. Trans. A 2013, 44, 911-922. [CrossRef]

23. Hielscher, R.; Schaeben, H. A novel pole figure inversion method: Specification of the MTEX algorithm. J. Appl. Crystallogr. 2008, 41, 1024-1037. [CrossRef]

24. Bachmann, F.; Hielscher, R.; Schaeben, H. Texture Analysis with MTEX-Free and Open Source Software Toolbox. SSP 2010, 160, 63-68. [CrossRef]

25. Haase, C.; Ingendahl, T.; Güvenc, O.; Bambach, M.; Bleck, W.; Molodov, D.A.; Barrales-Mora, L.A. On the applicability of recovery-annealed twinning-induced plasticity steels: Potential and limitations. Mater. Sci. Eng. A 2016, 649, 74-846. [CrossRef]

26. Haase, C.; Barrales-Mora, L.A.; Molodov, D.A.; Gottstein, G. Application of Texture Analysis for Optimizing Thermo-Mechanical Treatment of a High Mn TWIP Steel. AMR 2014, 922, 213-218. [CrossRef]

27. Haase, C.; Zehnder, C.; Ingendahl, T.; Bikar, A.; Tang, F.; Hallstedt, B.; Hu, W.; Bleck, W.; Molodov, D.A. On the deformation behavior of $\mathrm{k}$-carbide-free and k-carbide-containing high-Mn light-weight steel. Acta Mater. 2017, 122, 332-343. [CrossRef]

(C) 2019 by the authors. Licensee MDPI, Basel, Switzerland. This article is an open access article distributed under the terms and conditions of the Creative Commons Attribution (CC BY) license (http://creativecommons.org/licenses/by/4.0/). 